\begin{abstract}
Although it has been shown that killer cell immunoglobulin-like receptors (KIRs) on peripheral lymphocytes are upregulated by interleukin-2 (IL-2), which activates natural killer (NK) activity, it has not been demonstrated whether the expression of KIRs is related to NK activity. Therefore, we investigated the association between the KIR expression on lymphocytes and NK activity. CD158a/b expression on lymphocytes obtained from 37 subjects was analyzed using flow cytometry. Simultaneously, NK activity was measured each sample using a ${ }^{51} \mathrm{Cr}$ release assay. Additionally, lymphocytes were cultured in RPMI 1640 medium with or without IL-2 for $48 \mathrm{~h}$, and then their CD158a/b expression and NK activity was analyzed. CD158a/b expression was significantly correlated with NK activity. Especially, the percentage of $\mathrm{CD16}+\mathrm{CD158a}+$ and $\mathrm{CD8}+$ $\mathrm{CD158a} / \mathrm{b}+$ cells in lymphocytes showed a highly significant correlation with NK activity. However, analysis of $\mathrm{CD8}+$ and $\mathrm{CD16}+$ cells revealed that there was only a significant correlation between the percentage of $\mathrm{CD8}+\mathrm{CD158a}+$ cells among only CD8 + cells and NK activity. The upregulation of $\mathrm{CD16}+\mathrm{CD158a}+/ \mathrm{b}+$ cells in response to $\mathrm{IL}-2$ tended to be related to the increase of $\mathrm{NK}$ activity, but the relationship was not significant. In conclusion, the level of KIR expression was correlated with NK activity, and $\mathrm{IL}-2$ treatment resulted in an increase of NK activity as well as KIR expression, suggesting that upregulation of KIRs enhances the ability to sort target cells, such as virus-infected cells from uninfected cells, according to major histocompatibility complex class I expression.
\end{abstract}

Key words: Killer cell immunoglobulin-like receptors, Natural killing activity, Major histocompatibility complex class I, Inactivation

\section{Natural killer cytolytic activity is associated with the expression of killer cell immunoglobulin-like receptors on peripheral lymphocytes in human}

\author{
Toshiaki Kogure ${ }^{1, C A}$, Naoki Mantani ${ }^{1}$, Shinya Sakai ${ }^{2}$, \\ Yutaka Shimada ${ }^{2}$, Jun'ichi Tamura ${ }^{3}$ and \\ Katsutoshi Terasawa ${ }^{2}$
}

${ }^{1}$ Department of Integrated Japanese Oriental Medicine, School of Medicine, Gunma University, 3-39-22 Showa-machi, Maebashi Gunma 371-8511, Japan; ${ }^{2}$ Department of Japanese Oriental Medicine, Faculty of Medicine, Toyama Medical and Pharmaceutical University, 2630 Sugitani, Toyama 930-0194, Japan; ${ }^{3}$ Department of General Medicine School of Medicine, Gunma University, 3-39-22 Showa-machi, Maebashi Gunma 371-8511, Japan

\author{
${ }^{\mathrm{CA}}$ Corresponding author \\ Tel/Fax: +81272208666 \\ E-mail: tkogure@showa.gunma-u.ac.jp
}

\section{Introduction}

Natural killer (NK) cells are a discrete population of lymphocytes characterized in humans by the expression of CD16 and CD56 cell surface antigens. ${ }^{1} \mathrm{NK}$ cells are most noted for their in vitro ability to spontaneously lyse transformed or virus-infected and some normal cells, and are also potent producers of lymphokines, predominantly interferon- $\gamma$ and tumor necrosis factor $\alpha$. Given their rapid activation during an immune response and their dual role in cellmediated cytotoxicity and lymphokine production, NK cells are considered an important component of natural resistance, active as a first line of defense against infectious agents.

Although the exact mechanisms that NK cells utilize to recognize and lyse target cells have remained poorly understood, the molecular cloning of novel NK receptors was achieved in $1995,{ }^{2-4}$ and it has subsequently been shown that these receptors, which are now called killer cell immunoglobulin-like receptors (KIRs), transmit positive and/or negative signals. ${ }^{5,6}$ It is now widely accepted that the expression of KIRs is involved in the cytolytic function of NK cells, as demonstrated by a number of studies focusing on these receptors. ${ }^{7}$

We previously reported that the expression of both KIR2DL1 and KIR2DS1 (CD158a), and KIR2DL2, KIR2DL3 and KIR2DS2 (CD158b) on lymphocytes is upregulated by interleukin (IL)-2 but not by interferon- $\gamma$ or IL-4, although IL-2 enhances the cytotoxicity of NK cells. ${ }^{8}$ It has been speculated that the upregulation of KIRs by IL-2 results in enhanced ability to sort target cells such as virus-infected cells from uninfected cells according to major histocompatibility complex (MHC) class I expression. However, there has been no report of any investigation demonstrating an association between NK cytolytic activity and KIRs expression. In this study, we 
examined their relationship using peripheral blood lymphocytes in humans.

\section{Methods}

\section{Reagents}

Fluorescein isothiocyanate (FITC)-conjugated antihuman CD8, FITC-anti-human CD16, phycoerythrin (PE)-conjugated anti-human CD158a (EB6) and PEconjugated anti-human CD158b (GL183) were purchased from Immunotech (Marseille, France). Recombinant human IL-2 was obtained from Pharmabiotechnology (Hanover, Germany).

\section{Cells}

Peripheral blood mononuclear cells obtained from 37 volunteers (24 females and 13 males; age (mean \pm standard deviation), $66.3 \pm 25.4$ years; range, $25-86$ years) were separated from heparinized blood by Lymphoprep (Nyegaard, Oslo, Norway) gradient cenfugation. ${ }^{9}$ Each peripheral blood mononuclear cell sample was a incubated in culture dish in a humidified $5 \% \mathrm{CO}_{2} / 95 \%$ air atmosphere at $37^{\circ} \mathrm{C}$ for $60 \mathrm{~min}$. After the incubation, non-adherent cells were collected. These cell suspensions were washed twice in phosphate-buffered saline (PBS).

\section{Cell culture}

One million cells were cultured in RPMI 1640 medium supplemented with $10 \%$ fetal calf serum (Biological Industries, Israel) in tissue culture dishes (Becton Dickinson, Flanklin, NJ, USA). The cell cultures were incubated in medium only or medium containing IL-2 at $100 \mathrm{U} / \mathrm{ml}$ in a humidified $5 \% \mathrm{CO}_{2} /$ $95 \%$ air atmosphere at $37^{\circ} \mathrm{C}$ for $48 \mathrm{~h}$. After each incubation, cells were collected and their surface antigens were analyzed using flow cytometry (Epics XL; Beckman Coulter, Marseille, France). Simultaneously, the NK activity in each sample was measured using a ${ }^{51} \mathrm{Cr}$-release assay. Each experiment was carried out in duplicate.

\section{Cell phenotype}

Surface phenotyping was carried out using a twocolor immunofluorescence staining technique, with isotype-specific mouse anti-human antibody conjugated with either FITC or PE. ${ }^{10}$ Each sample of stained cells was suspended in $0.5 \mathrm{ml}$ of PBS and analyzed by flow cytometry. Lymphocyte subsets were identified by gating analysis and fluorescence profiles were obtained for 10,000 cells of each sample. Negative controls for each experiment were performed with FITC-labeled and PE-labeled mouse immunoglobulin G.

\section{NK cytolytic activity}

NK activity was assessed against K562, a myelogeneous leukemia cell line, in a $3 \mathrm{~h}^{51} \mathrm{Cr}$-release assay as described previously. The effecter cells were mixed with labeled target cells at various cell concentrations to give effecter to target ratios of 20:1 or 10:1. Duplicate samples were prepared for each ratio. The supernatants were withdrawn after a $4 \mathrm{~h}$ incubation period, and the ${ }^{51} \mathrm{Cr}$ released from lysed targets was quantitated in a gamma counter (Packard Instrument Co., Boston, MA, USA). Incubation of targets with medium or saponin $(7 \mathrm{mg} / \mathrm{ml})$ and ethylenediamine tetraacetic acid $(0.1 \mathrm{mg} / \mathrm{ml})$ was used to determine spontaneous and maximal release, respectively. The percent cytotoxicity was calculated by the formula: (cpm of effecter cells $-\mathrm{cpm}$ of spontaneous release)/(cpm of maximal release cpm of spontaneous release) $\times 100$.

\section{Statistical analysis}

Data are expressed as mean (standard deviation) values. All data were collected in a computer database and analyzed using the StatView-J 4.02 program (Abacus Concept, Berkeley, CA, USA). Spearman rank correlation analysis was performed between each part of NK activity and KIR expression. For all statistical tests, correlations were regarded as statistically significant if $p<0.05$.

\section{Results}

The relationship between the percentage of CD158a + or CD158b + cells in lymphocytes and NK cytolytic activity

There was no relationship between the expression of CD16 and NK cytotoxicity (Table 1). In contrast, the expression of CD158a or CD158b correlated with the NK cytolytic activity significantly (Table 1 ). The correlation of CD158a expression with NK cytotoxicity is shown in Fig. 1.

\section{The relationship between the percentage of $\mathrm{CD} 8+\mathrm{CD} 158 \mathrm{a}+/ \mathrm{b}+$ or CD16 + CD158a $+/ \mathrm{b}+$ cells in lymphocytes and NK cytolytic activity}

There was a significant relationship between the percentage of $\mathrm{CD} 8+\mathrm{CD} 158 \mathrm{a}+/ \mathrm{b}+$ cells and $\mathrm{NK}$ cytolytic activity (Table 1). Similarly, the percentage of $\mathrm{CD} 16+\mathrm{CD} 158 \mathrm{~b}+$ cells tended to be correlated with NK cytolytic activity, although the correlation was not significant (Table 1). 
Table 1. Correlation of NK cytolytic activity with several cell surface antigens

\begin{tabular}{lcc}
\hline NK cytolytic activity V.S.* & Probability* $^{*}$ & Linear regression coefficient \\
\hline CD16 & 0.086 & 0.295 \\
CD158a & 0.010 & 0.424 \\
CD158b & 0.032 & 0.362 \\
CD8CD158a & 0.008 & 0.432 \\
CD8CD158b & 0.006 & 0.458 \\
CD16CD158a & 0.018 & 0.398 \\
CD16 CD158b & 0.130 & 0.257 \\
CD8+CD158a+ cell/CD8+ cell & 0.026 & \\
CD8+CD158b + cell/CD8+ cell & 0.117 & 0.375 \\
CD16+CD158a + cell/CD16+ cell & 0.163 & 0.270 \\
CD16+CD158b + cell/CD16+ cell & 0.790 & 0.241 \\
\end{tabular}

*If probability $<0.05$, correlations are regarded as ststistically significant. $* *$ V.S. $=$ versus.

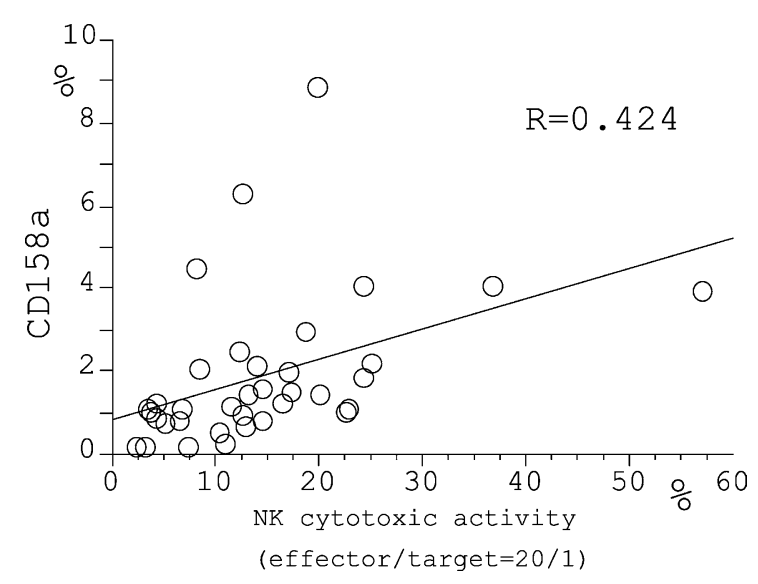

FIG. 1. The correlation of CD158a + cells with natural killing activity is shown. $P=0.0099, r=0.424$.

The relationship between the percentage of $\mathrm{CD} 158 \mathrm{a} / \mathrm{b}+$ cells in CD8 + or CD16 + cells and NK activity

To investigate the significance of the KIR expression on $\mathrm{CD} 8+$ or $\mathrm{CD} 16+$ cells, we further analyzed the association between the percentage of $\mathrm{CD} 158 \mathrm{a} / \mathrm{b}+$ cells in CD8 + or CD16 + cells and NK activity. There was a tendency toward a correlation between the percentage of CD8 + CD158a + cells in CD8 + cells and NK cytolytic activity. However, we could not find a significant correlation between the percentage of $\mathrm{CD} 8+\mathrm{CD} 158 \mathrm{~b}+$ cells/CD8 + cells, CD16+ $\mathrm{CD} 158 \mathrm{a}+$ cells/CD16 + cells or CD16 +CD158b + cells/CD16+ cells, and NK cytotoxicity (Table 1 ).

\section{The change of CD158a/b expression and NK activity when lymphocytes are treated with IL-2}

We assessed the CD158a/b expression and NK cytolytic activity after treatment of eight donors with IL-2. NK cytotoxicity increased by treatment of IL-2 as previously shown $^{8,11}$ (Fig. 2A). Simultaneously, the percentage of $\mathrm{CD} 158 \mathrm{a}+$ and $\mathrm{CD} 158 \mathrm{~b}+$ cells increased (Fig. 2B). In addition, the percentage of $\mathrm{CD} 8+\mathrm{CD} 158 \mathrm{a}+/ \mathrm{b}+$ cells and CD16+CD158a+/ $\mathrm{b}+$ cells also increased in parallel with the increase of NK cytotoxicity (Fig. 2B). The increases of the $\mathrm{CD} 158 \mathrm{a}+/ \mathrm{b}+$ cell population and NK cytolytic activity by treatment with IL-2 were dose dependent from 10 to $200 \mathrm{U} / \mathrm{ml}$ (data not shown).

\section{Discussion}

In this study, we first showed that NK cytolytic activity correlates with the expression of KIRs recognized by CD158a/b in humans. Second, we showed that upregulation of the KIR expression was accompanied by an increase of NK cytotoxicity when lymphocytes were incubated with medium plus IL2. The present findings support the speculation described earlier. Namely, when the cytolytic activity increases, the expression of KIRs also increased. Alternatively, the percentage of CD16+CD158b + cells did not correlate with NK cytolytic activity, although the percentage of CD16+CD158a + and $\mathrm{CD} 8+\mathrm{CD} 158 \mathrm{a}+/ \mathrm{b}+$ cells correlated with it in our study. NK cytolytic activity is dependent on the signaling balance of KIRs, activating receptors and the expression of their ligands. Therefore, there is a not always a relationship between the NK cytolytic activity and the proportion of KIR-positive cells in the cross-sectional analysis. In contrast, the percentage of each cell population is related to the NK cytolytic activity after treatment with IL-2, indicating that the expression of KIRs is upregulated when NK activity increases. These findings are in accord with recently published data showing that downregulation of KIRs is accompanied by a decrease of natural killing activity. ${ }^{12}$ However, it is unclear whether the upregulation of KIRs occurs before or after enhancement of NK activity.

Analysis of the percentage of KIR-expressing cells among CD8+ or CD16+ cells revealed that the percentage of CD158a expression on CD8 + cells, but not on CD16 + cells, correlated with NK activity. We cannot yet explain these phenomena from the 


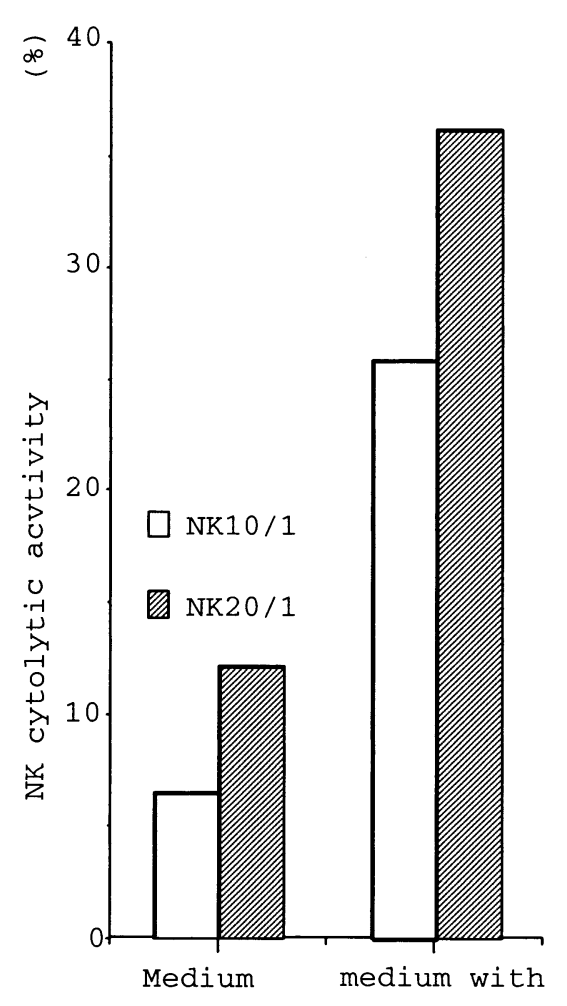

(A) alone IL-2 $100 \mathrm{U} / \mathrm{ml}$

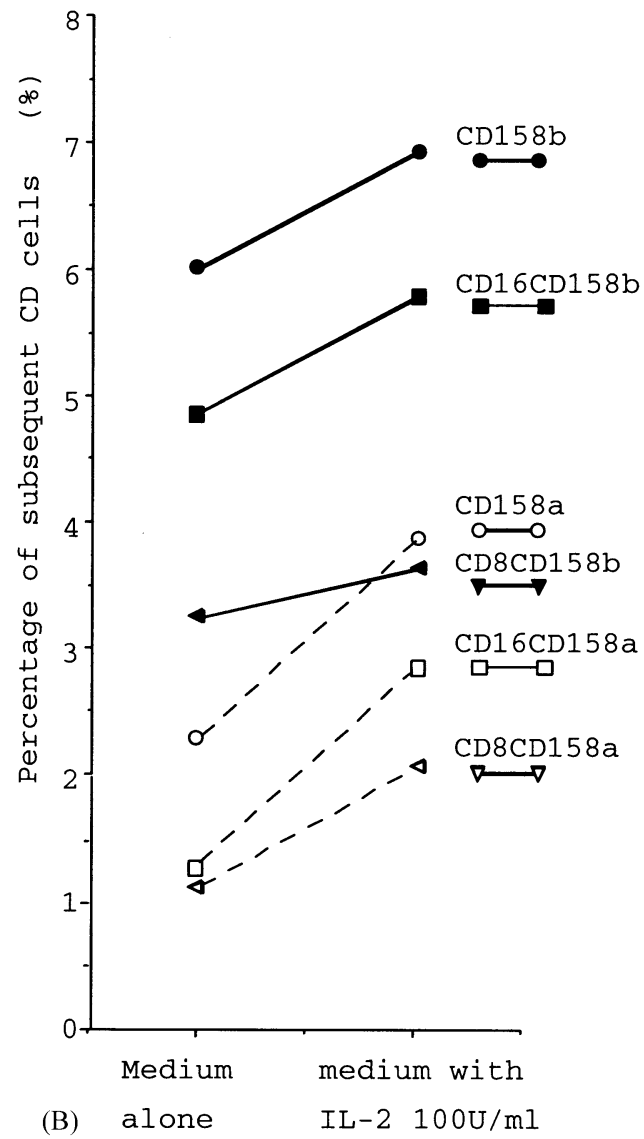

FIG. 2. The change of CD158a/b expression and NK activity when lymphocytes are treated with medium alone or medium containing IL-2 at $100 \mathrm{U} / \mathrm{ml}$. Eight of 35 donors were assessed for CD158a/b expression and NK cytolytic activity. (A) NK cytolytic activity in bars representing medium alone and medium with IL-2. (B) Six lines presenting the percentage increase of subsequent $C D$ cells. The percentage of each $C D$ cell was increased significantly by the treatment of IL-2. The change of each $\mathrm{CD}$ cell was in parallel to the increase of NK activity.

immunological viewpoint. It is possible that the expression of KIRs on CD8 + cells is more important functionally than inhibitory receptors on CD16+ cells. Although the function of KIRs in CD8 $+\mathrm{T}$ cells is still obscure, these KIRs probably prevent autoaggression by cytotoxic $\mathrm{T}$ cells specific for selfantigens. ${ }^{13,14}$ In $\mathrm{T}$ cells, the expression of the activating receptors such as TCR and CD2, and the MHCrestricted killing activity, are not affected by KIR downregulation. ${ }^{15}$ Thus, the only known fail-safe system to escape attack by cytotoxic $\mathrm{T}$ cells is the inactivation by negative signals from KIRs on $\mathrm{T}$ cells. Indeed, in NK cells, activating receptors were found to be decreased by KIR-MHC class I interactions, and this receptor downregulation was correlated with a deficiency in the NK activity as well as CD16mediated killing activity. ${ }^{12,16}$ These phenomena appeared to be specific to NK cells.

KIRs recognized by CD158a/b consist of two kinds of receptors. ${ }^{17,18}$ CD158a reacts with KIR2DL1 (inhibitory receptor (IR)) and KIR2DS1 (activating receptor (AR)), and $\mathrm{CD} 158 \mathrm{~b}$ reacts with KIR2DL2, KIR2DL3 (IR) and KIR2DS2 (AR). CD158a/b monoclonal antibodies (mAb) cannot distinguish between these receptors. Furthermore, the ligands that react with AR have been identified as ligands that react with IR and, importantly, the CD158b mAb we used bound equally to the AR and IR, ${ }^{19}$ making it difficult to explain NK cell regulation. To date, it has been considered that the activating signal can be overridden by a dominant-negative signal from IR when IR interacts with its ligand on the target cell, although $\mathrm{AR}$, when occupied, triggers lysis of the target cell being recognized. ${ }^{20,21}$ These insights led us to speculate that KIRs increase as part of the defense system of non-infected cells when NK cells are activated by viral infection, although other activating receptors such as $\mathrm{CD}_{6} 9^{22}$ and $2 \mathrm{~B} 4^{23}$ might be upregulated. However, several critical questions remain. The importance of AR upregulation parallel to IR upregulation is still not clear in NK cell activation. Recently, a biphasic response of NK cells expressing both $\mathrm{AR}$ and IR has been demonstrated. ${ }^{24}$ High concentrations of CD158b mAb transmitted inhibitory signals to NK cells, whereas low concentrations transmitted activating signals. ${ }^{24}$ Warren et al. speculated that there is a fail-safe mechanism for activating NK cells if other NK cell-activating receptors or target 
cell ligands to activate those receptors are not present when histocompatibility antigen (HLA) concentrations on target cells are below that capable of inhibiting NK cell function. In our study, NK cytolytic activity correlated with the expression of CD158a/brecognizing receptors. A possible rationale for the upregulation of both IR and AR during the course of viral infection or neoplastic disease is that NK cells are capable of lysing cells expressing low levels of HLA in early stages of diseases independently of other activating receptors, and NK cells are also inactivated by negative signals from IR if activating receptor-expressing NK cells encounter normal cells on which HLA molecules are highly expressed. Therefore, we speculate that it is beneficial for the bio-defense system to upregulate the expression of KIRs when NK cells acquire enhanced cytotoxic activity. Recently, Huard et al. reported that KIR downregulation on NK cells is associated with the downregulation of activating receptors such as $2 \mathrm{~B} 4$ as well as with a lack of cell responsiveness12. Thereafter, several safety mechanisms may function to protect normal HLA-expressing cells.

ACKNOWLEDGEMENTS. The authors wish to thank T. S. Oda and N. Kuribayashi for excellent assistance, and thank C. Haoka and S. Watanabe for secretary work.

\section{References}

1. Trinchieri G. Biology of natural killer cells. Adv Immunol 1989; 47 $187-376$.

2. Colonna M, Samaridis J. Cloning of immunoglobulin-superfamily members associated with HLA-C and HLA-B recognition by human natural killer cells. Science 1995; 268: 405-408.

3. D'andrea A, Chang C, Franz-Bacon K, McClanahan T, Phillips JH, Lanier LL. Molecular cloning of NKB1 a natural killer cell receptor for HLA-B allotypes. J Immunol 1995; 155: 2306-2310.

4. Wagtmann N, Biassoni R, Cantoni C, et al. Molecular clones of the p58 NK cell receptor reveal immunoglobulin-related molecules with diversity in both the extra- and intracellular domains. Immunity 1995; 2 $439-449$.

5. Vivier E, Daeron M. Immunoreceptor tyrosine-based inhibition motifs. Immunol Today 1997; 18: 286-291

6. Binstadt BA, Brumbaugh KM, Dick CJ, et al. Sequential involvement of Lck and SHP-1 with MHC-recognizing receptors on NK cells inhibits FcRinitiated tyrosine kinase activation. Immunity 1996; 5: 629-638.
7. Lanier LL. NK cell receptors. Annu Rev Immunol 1998; 16: 359-393.

8. Kogure T, Fujinaga H, Niizawa A, et al. Killer-cell inhibitory receptors, $\mathrm{CD} 158 \mathrm{a} / \mathrm{b}$, are upregulated by interleukin-2, but not interferon- $\gamma$ or interleukin-4. Mediat Inflamm 1999; 8: 295-300.

9. Ross G, Winchester RJ. Methods for enumerating lymphocyte population. In: Rose NR, Friedmann H, eds. Manual of Clinical Immunology, Washington, DC: American Society for Microbiology, 1986: 213.

10. Frohhn C, Schlenke P, Kirscner H. The repertoire of HLA-Cw-specific NK cell receptors CD158a/b (EB6 and GL183) in individuals with different HLA phenotypes. Immunology 1997; 92: 567-570.

11. Kogure T, Niizawa A, Hai LX, et al. Effect of interleukin 2 on killer cell inhibitory receptors in patients with rheumatoid arthritis. Ann Rheum Dis 2001; 60: 166-169.

12. Huard B, Karlsson L, Triebel F. KIR down-regulation on NK cells is associated with down-regulation of activating receptors and NK cell inactivation. Eur J Immunol 2001; 31: 1728-1735.

13. McMahon CW, Raulet DH. Expression and function of NK cell receptors in CD8 + T cells. Curr Opin Immunol 2001; 13: 465-470.

14. Chao KH, Wu MY, Chen CD, Yang JH, Yang YS, Ho HN. The expression of killer cell inhibitory receptors on natural killer cells and activation status of $\mathrm{CD} 4+$ and $\mathrm{CD} 8+\mathrm{T}$ cells in the decidua of normal and abnormal early pregnancies. Hum Immunol 1999; 60: 791-797.

15. Huard B, Karlsson L. KIR expression on self-reactive CD8+ T cells is controlled by T cell receptor engagement. Nature 2000; 403: 325-328.

16. Mandelboim O, Malik P, Davis DM, Jo CH, Boyson JE, Strominger JL. Human CD16 as a lysis receptor mediating direct natural killer cell cytotoxicity. Proc Natl Acad Sci USA 1999; 96: 5640-5644.

17. Colonna M. Specificity and function of immunoglobulin superfamily NK cell inhibitory and stimulatory receptors. Immunol Rev 1997; 155: $127-$ 133

18. Morreta A, Biassoni R, Bottino C, et al. Major histcompatibility complex class I-specific receptors on human natural killer and $\mathrm{T}$ lymphocytes. Immunol Rev 1997; 155: 105-117.

19. Vales-Gomez M, Reyburn HT, Erskine RA, Strominger J. Differential binding to HLA-C of p50-activating and p58-inhibitory natural killer cell receptors. Proc Natl Acad Sci USA 1998; 95: 14326-14331.

20. Kaufman DS, Schoon RA, Robertson MJ, Leibson PJ. Inhibition of selective signaling events in natural killer cells recognizing major histocompatibility complex class I. Proc Natl Acad Sci USA 1995; 92 6484-6488.

21. Vitale M, Sivori S, Pende D, Morreta L, Morreta A. Coexpression of two functionally independent p58 inhibitory receptors in human natural killer cell clones results in the inability to kill all normal allogeneic target cells. Proc Natl Acad Sci USA 1995; 92: 3536-3540

22. Morreta A, Poggi A, Pende D, et al. CD69-mediated pathway of lymphocyte activation: anti-CD69 monoclonal antibodies trigger the cytolytic activity of different lymphoid effecter cells with the exception of cytolytic T lymphocytes expressing T cell receptor alpha/beta. J Exp Med 1991; 174: $1393-1398$.

23. Nakajima $\mathrm{H}$, Cella $\mathrm{M}$, Langen $\mathrm{H}$, Friedlein A, Colonna M. Activating interactions in human NK cell recognition: the role of 2B4-CD48. Eur J Immunol 1999; 29: 1676-1683.

24. Warren HS, Cambell AJ, Waldron JC, Lanier LL. Biphasic response of NK cells expressing both activating and inhibitory killer Ig-like receptors. Int Immunol 2001; 13: 1043-1052.

\section{Received 9 January 2003}

Accepted 3 February 2003 


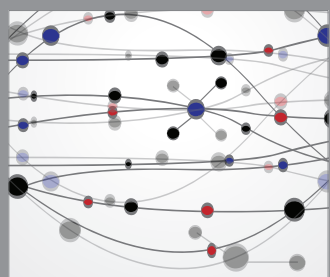

The Scientific World Journal
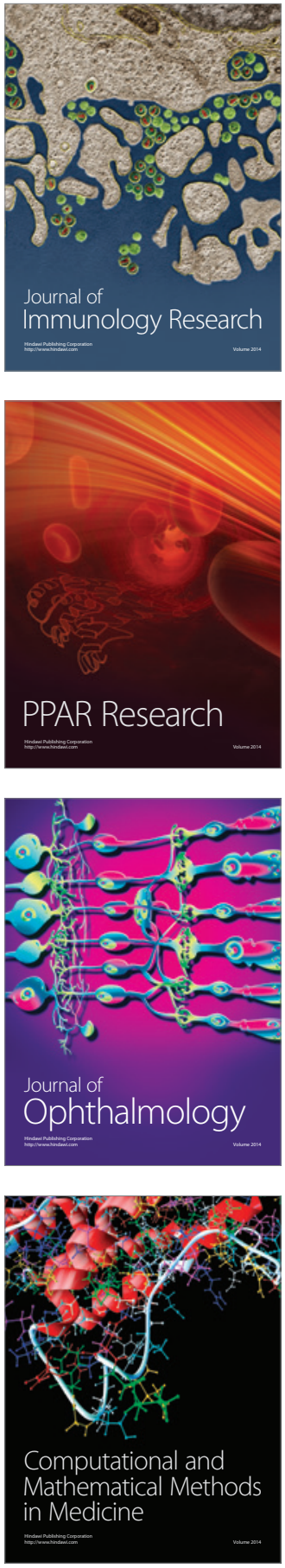

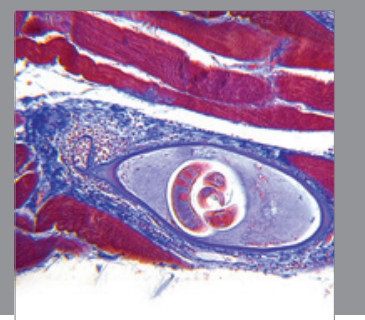

Gastroenterology

Research and Practice
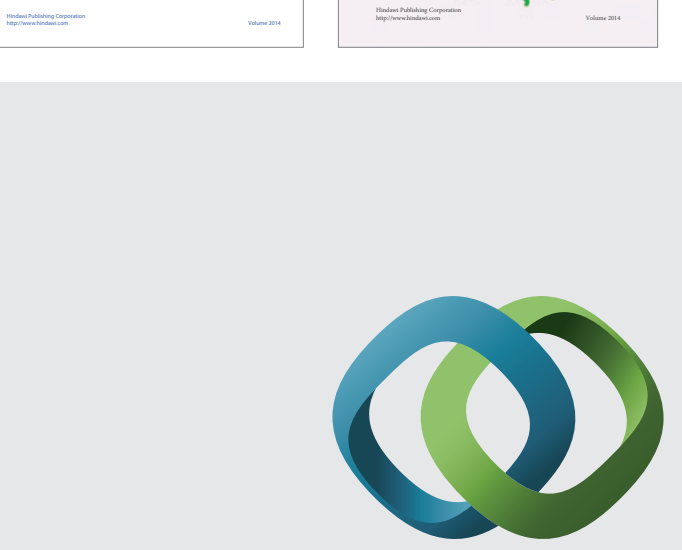

\section{Hindawi}

Submit your manuscripts at

http://www.hindawi.com
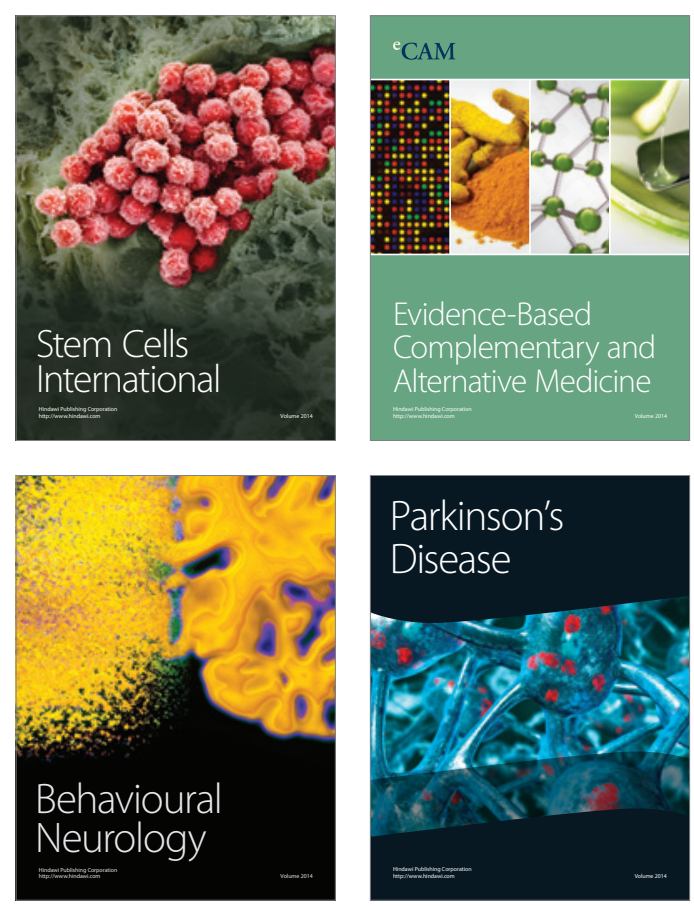

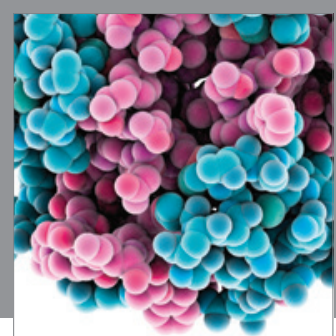

Journal of
Diabetes Research

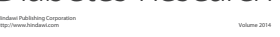

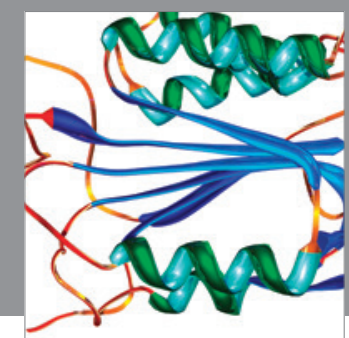

Disease Markers
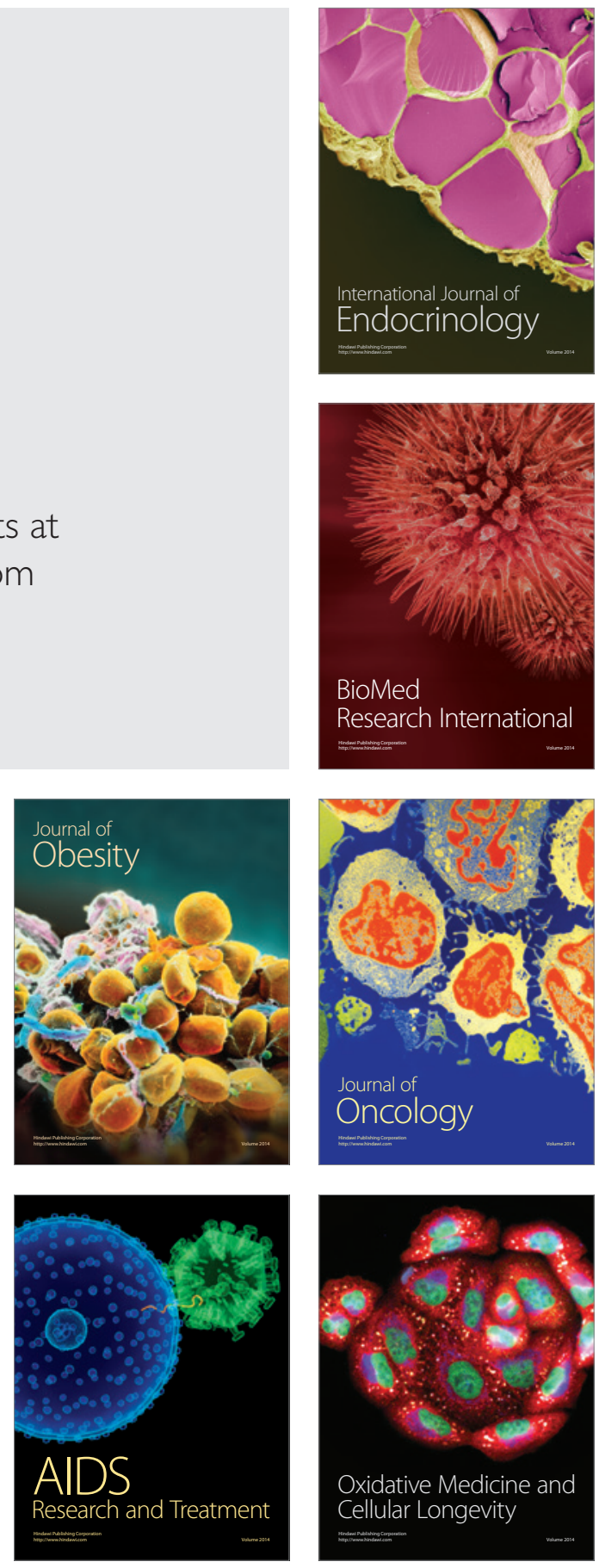